\title{
Construção e evidências de validade da Escala de Habilidades Parentais em Disciplina Positiva
}

\author{
Laura C. M. Soares e José Augusto E. Hernandez \\ Departamento de Psicologia Cognitiva e Desenvolvimento, Mestrado em Psicologia Social, \\ Universidade do Estado do Rio de Janeiro (Uerj)
}

Submissão: 26 jul. 2020.

Aceite: 15 jun. 2021.

\section{Nota dos autores}

Laura C. M. Soares (iD https://orcid.org/00oo-0003-3282-199X

José Augusto E. Hernandez (iD https://orcid.org/0ooo-0001-9402-7535

Esta pesquisa foi contemplada com uma bolsa de mestrado da Coordenação de Aperfeiçoamento de Pessoal de Nível Superior (Capes).

Correspondências referentes a este artigo devem ser enviadas para José Augusto E. Hernandez, Rua São Francisco Xavier, 524, $10^{\circ}$ andar, sala 10028D, Maracanã, Rio de Janeiro, RJ, Brasil. CEP 20050-900.E-mail: hernandez.uerj@gmail.com 


\title{
Resumo
}

Este artigo apresenta a construção e evidências de validade de um instrumento para mensurar habilidades parentais baseado na Disciplina Positiva, abordagem que auxilia pais e cuidadores a ensinar habilidades de vida para suas crianças. Os itens foram formulados a partir de revisão teórica sobre estilos parentais, Terapia do Esquema e Disciplina Positiva e posteriormente avaliados por cinco juízas experts e cinco indivíduos do público-alvo. Após as avaliações, oito itens foram excluídos e outros sofreram alterações, chegando-se a uma versão-piloto da Escala de Habilidades Parentais em Disciplina Positiva (EHPDP) com 28 itens. Os dados foram coletados de uma amostra de 281 mães com filhos de 4-12 anos. A análise fatorial exploratória revelou uma estrutura de 16 itens divididos em três fatores. O Alfa de Cronbach e a confiabilidade composta indicaram adequada consistência interna para o instrumento. A correlação de Pearson revelou evidências de validade convergente e discriminante com as versões brasileiras validadas do Questionário de Estilos e Dimensões Parentais e da Escala de Depressão, Ansiedade e Estresse. Os resultados indicam que a EHPDP é um instrumento válido e confiável para mensurar habilidades parentais em Disciplina Positiva.

Palavras-chave: Disciplina Positiva, habilidades parentais, estilos parentais, validade, psicometria

\section{CONSTRUCTION AND EVIDENCE OF VALIDITY OF THE POSITIVE DISCIPLINE PARENTING SKILLS SCALE}

\begin{abstract}
This article presents the construction and evidence of validity of an instrument for measuring parenting skills based on Positive Discipline, an approach that helps parents and caregivers teach life skills to their children. The items were constructed based on a theoretical review of Parenting Styles, Schema Therapy, and Positive Discipline and were subsequently evaluated by five expert judges and five individuals from the target audience. Following these evaluations, eight items were excluded and others were changed, leading to the pilot version of the Positive Discipline Parenting Skills Scale (Escala de Habilidades Parentais em Disciplina Positiva - EHPDP), represented by 28 items. Data were collected from a sample of 281 mothers with children aged 4-12 years. Exploratory Factor Analysis revealed a structure of 16 items divided into three factors. Cronbach's Alpha and Composite Reliability indicated adequate internal consistency for the instrument. Pearson's correlation revealed evidence of convergent and discriminant validity with the validated Brazilian versions of the Parenting Styles and Dimensions Questionnaire and the Depression, Anxiety and Stress Scale. The results indicate that the EHPDP is a valid and reliable instrument to measure Positive Discipline parenting skills.
\end{abstract}

Keywords: Positive Discipline, parenting skills, parenting styles, validity, psychometrics 


\section{CONSTRUCCIÓN Y EVIDENCIAS DE VALIDEZ DE LA ESCALA DE HABILIDADES PARENTALES EN DISCIPLINA POSITIVA}

\section{Resumen}

Este artículo presenta la construcción y evidencias de validez de un instrumento para medir habilidades parentales basado en la Disciplina Positiva, un enfoque que ayuda a los padres y cuidadores a enseñar habilidades para la vida a sus hijos. Los ítems de la escala se formularon en base a una revisión teórica sobre estilos parentales, Terapia de Esquemas y Disciplina Positiva, siendo posteriormente evaluados por cinco jueces expertos y cinco individuos del público destinatario. Después de las evaluaciones, ocho ítems fueron excluidos y otros sufrieron cambios, llegando a la versión piloto de la Escala de Habilidades Parentales en Disciplina Positiva (EHPDP), con 28 ítems. Los datos se obtuvieron de una muestra de 281 madres con niños de 4-12 años. El análisis factorial exploratorio reveló una estructura de 16 ítems divididos en tres factores. El Alfa de Cronbach y la fiabilidad compuesta indicaron una consistencia interna adecuada para el instrumento. La correlación de Pearson reveló evidencia de validez convergente y discriminante con las versiones brasileñas validadas del Cuestionario de Estilos y Dimensiones Parentales y la Escala de Depresión, Ansiedad y Estrés. Los resultados indican que la EHPDP es un instrumento válido y confiable para medir las habilidades parentales en Disciplina Positiva.

Palabras clave: Disciplina Positiva, habilidades parentales, estilos parentales, validez, psicometría 
As relações pais-filhos e sua influência no desenvolvimento emocional, social e cognitivo dos filhos têm sido objeto de muitos estudos nas últimas décadas (Baumrind, 1966, 1967, 1971; Lamborn et al., 1991; Paiva \& Ronzani, 2009; Granja \& Mota, 2018). Nesse sentido, Baumrind $(1966,1967)$ criou um modelo teórico propondo a existência de três estilos parentais, os quais estariam categorizados pelo controle parental e pelo afeto em relação à criança.

O grau em que os pais demonstram comportamentos nessas dimensões define seu estilo parental como autoritário, permissivo ou autoritativo (Baumrind, 1967). Assim, o estilo autoritário oferece pouco afeto e muito controle, valorizando a obediência e utilizando-se de punições; o estilo permissivo é afetuoso, mas evita o estabelecimento de limites e restrições; e o estilo autoritativo dá afeto enquanto exerce controle firme, reconhecendo os interesses da criança e incentivando o diálogo (Granja \& Mota, 2018; Oliveira et al., 2018).

Estudos nacionais e internacionais relacionam o estilo autoritativo a aspectos positivos de desenvolvimento dos filhos, como maior regulação emocional, habilidades sociais apropriadas e mais felicidade (Baumrind, 1971), maior competência social e menos problemas de comportamento (Lamborn et al., 1991), melhor saúde mental (Lamborn et al., 1991; Hutz \& Bardagi, 2006; Uji et al., 2014), níveis mais altos de otimismo (Weber et al., 2003) e bem- estar (Boeckel \& Sarriera, 2006) e menor consumo de tabaco, álcool e outras drogas (Paiva \& Ronzani, 2009).

Contudo, foram encontradas relações entre os demais estilos e aspectos negativos dos filhos, como pouco controle emocional, baixos níveis de persistência diante de desafios e desafiadores quando seus desejos não foram atendidos (Baumrind, 1971), menor competência psicossocial e menos engajamento no ambiente escolar (Lamborn et al., 1991), maior disfunção psicológica (Lamborn et al., 1991; Hutz \& Bardagi, 2006; Uji et al., 2014), níveis mais baixos de otimismo (Weber et al., 2003) e bem-estar (Boeckel \& Sarriera, 2006), maior frequência de abuso de substâncias (Lamborn et al., 1991; Paiva \& Ronzani, 2009) e níveis maiores de problemas de comportamento (Lamborn et al., 1991; Tavassolie et al., 2016).

$\mathrm{O}$ avanço teórico proporcionado pelas pesquisas que investigavam as relações entre estilos parentais e aspectos psicossociais trouxe destaque na literatura para o estudo das correlações entre estilos de família e psicopatologias. Assim, na década de 1990 surgiu a Terapia do Esquema de Jeffrey Young, o primeiro modelo clínico de compreensão dos estilos parentais. Esse modelo propõe a existência de 18 esquemas iniciais desadaptativos cujo desenvolvimento ocorreria na infância e adolescência, com base em interações com núcleos familiares punitivos, frios, permissivos, hipercríticos, superprotetores ou invalidantes, levando à manifestação de transtornos psicológicos no futuro (Wainer et al., 2016).

A Disciplina Positiva (DP) foi desenvolvida por Nelsen (2015) na década de $1980 \mathrm{com}$ base nos ensinamentos de Alfred Adler e Rudolf Dreikurs. Sua principal finalidade consiste em auxiliar pais e cuidadores a ensinar importantes habilidades de vida para suas crianças, tanto 
por meio da leitura de livros sobre o tema, quanto pela participação em treinamentos e workshops. Sendo assim, pode ser utilizada como ferramenta para promoção de habilidades dos pais, os quais poderiam passar a contribuir de forma mais efetiva para o desenvolvimento sadio de suas crianças, o que poderia por sua vez vir a prevenir a manifestação de transtornos psicológicos por elas no futuro.

A DP ensina conceitos que são bastante representativos do estilo autoritativo de Baumrind (Carroll \& Hamilton, 2016). Ambos reconhecem a importância de oferecer afeto e apoio, de estabelecer limites de forma respeitosa e de auxiliar a criança a se tornar autônoma. Porém, a DP vai além do que é proposto pelo estilo autoritativo, propondo também interações que promovam o desenvolvimento de importantes habilidades de vida, como autoconsciência, autorregulação, responsabilidade, solução de problemas e resiliência (Glenn \& Nelsen, 2010; Nelsen, 2015). Portanto, por tratar-se de uma abordagem com um repertório mais amplo que o previsto pelo estilo autoritativo, ela é capaz de promover o desenvolvimento de outros aspectos igualmente importantes das crianças, como as habilidades socioemocionais.

Ao longo das últimas décadas, muitos livros sobre DP foram publicados e uma organização foi criada, a Positive Discipline Association, hoje com presença global e responsável por certificar educadores parentais em DP ao redor do mundo, os quais oferecem à comunidade treinamentos e workshops com a finalidade de promover o desenvolvimento das habilidades parentais sugeridas por essa abordagem. Entretanto, devido à carência de estudos sobre o tema, sabe-se muito pouco sobre a efetividade dos programas propostos, que são ensinados ao longo de uma série de encontros, ou de forma autodidata a partir da leitura dos livros e outros materiais educativos. Logo, é de extrema importância que sejam realizadas pesquisas com o objetivo de investigar se esses treinamentos para pais são eficazes, se as mudanças nos estilos parentais se sustentam e por quanto tempo. Para que seja possível essa análise, é necessário um instrumento que mensure tais práticas.

Os estilos parentais abarcam formas diferentes de interação pais-filhos, tanto positivas para o desenvolvimento das crianças, como o estilo autoritativo, quanto prejudiciais, como o autoritário e o permissivo (Baumrind, 1971). Já a DP consiste numa proposta similar ao estilo autoritativo, ou seja, também benéfica para o desenvolvimento dos filhos (Carroll \& Hamilton, 2016). Por sua vez, a Terapia do Esquema é um modelo clínico baseado em esquemas desadaptativos que seriam desenvolvidos a partir de interações prejudiciais entre a criança e sua família/cuidadores (Wainer et al., 2016).

No que tange às similaridades entre o estilo autoritativo e a DP, pode-se dizer que ambos reconhecem a importância de oferecer afeto/apoio, de estabelecer limites de forma respeitosa e de auxiliar a criança a se tornar autônoma, o que são comportamentos contrários aos característicos do estilo autoritário, como utilização de coerção física, punições e hostilidade verbal, e do permissivo, como a indulgência (Nelsen, 2015; Oliveira et al., 2018). 
O modelo conceitual da Terapia do Esquema é dividido em cinco domínios de esquemas. Estes consistem em intervalos temporais que vão do começo da infância ao início da adolescência, nos quais se espera que os cuidadores e o ambiente possam suprir algumas demandas psicológicas, também chamadas de "necessidades fundamentais", de forma que a criança desenvolva esquemas iniciais saudáveis (Wainer et al., 2016).

É importante destacar que tanto a Terapia do Esquema quanto a DP reconhecem a existência de "necessidades fundamentais" das crianças, como diz a primeira, ou "necessidades básicas", como define a segunda. Para a Terapia do Esquema, há cinco necessidades: aceitação e vínculos seguros; autonomia e competência; limites realistas; respeito às aspirações, aos desejos e à individualidade; e expressão legítima das emoções (Wainer et al., 2016). Já para a DP há quatro necessidades básicas: senso de aceitação, conexão e pertencimento; senso de autonomia e capacidade; habilidades sociais e de vida; e disciplina firme e gentil (Nelsen et al., 2018). Logo, as abordagens sugerem três necessidades comuns: aceitação/conexão, autonomia e percepção de capacidade e a definição de limites razoáveis e respeitosos.

Além disso, embora a DP não preveja no seu rol de necessidades o respeito às aspirações, aos desejos e à individualidade da criança nem a expressão legítima de suas emoções, ela aborda a importância desses dois aspectos em seus livros. Logo, em termos teóricos, a DP encontra-se totalmente alinhada ao que a Terapia do Esquema sugere como necessidades das crianças a serem supridas pelos seus cuidadores.

Já como diferenças, temos que a DP prevê a necessidade do desenvolvimento de habilidades sociais e de vida, como autorregulação, autocontrole, autodisciplina, empatia, respeito, solução de problemas, cooperação, flexibilidade etc., e a Terapia do Esquema prevê apenas o autocontrole e autodisciplina, que estariam dentro do domínio de autonomia e desempenho prejudicados (Glenn \& Nelsen, 2010; Nelsen, 2015; Wainer et al., 2016). Algo similar ocorre no estilo parental autoritativo, que também não prevê o desenvolvimento dessas importantes habilidades.

Uma revisão bibliográfica foi realizada em abril de 2019 no portal de periódicos da Coordenação de Aperfeiçoamento de Pessoal de Nível Superior (Capes) e no Google Acadêmico com a finalidade de verificar a existência de um instrumento válido e confiável para avaliar as habilidades parentais propostas pela DP. Utilizaram-se como palavras-chave de busca a expressão "Disciplina Positiva" associada ao termo "instrumento" ou "escala" ou "medida" e ao termo "Nelsen", assim como seus equivalentes em língua inglesa e espanhola. As palavras- chave deveriam estar contidas em qualquer lugar do artigo, o qual poderia ter sido publicado em qualquer ano. A pesquisa bibliográfica resultou em dois estudos que utilizaram os seguintes instrumentos para mensurar as habilidades parentais da DP: os Cuestionarios D.I.S.P.O., de Sánchez et al. (2010), e a Positive Discipline Parenting Scale, de Carroll e Hamilton (2016). Porém, ambos apresentam problemas em relação às suas propriedades psicométricas. 
A única análise estatística realizada no estudo dos Cuestionarios D.I.S.P.O. (Sánchez et al., 2010) foi o cálculo do Alfa de Cronbach, com a finalidade de verificar a confiabilidade. Esse cálculo foi realizado com base numa amostra de seis pais/mães e em outra amostra de 15 filhos, cujos resultados foram 0,68 e 0,51, respectivamente, o que é considerado abaixo do adequado. Além disso, como o tamanho dessas duas amostras foi muito pequeno, conclui-se que as evidências geradas não foram suficientes para atribuir fidedignidade à medida (Hair et al., 2018).

Em relação à Positive Discipline Parenting Scale (Carroll \& Hamilton, 2016), seus sete itens foram adaptados de um questionário de 18 itens desenvolvido num estudo de McVittie e Best (2009) para avaliar o efeito de um treinamento adleriano para pais. Os autores reconhecem que seus itens não são capazes de representar a extensão do construto proposto pela DP, o que demonstra a necessidade de uma medida mais abrangente. Além disso, no que tange à análise de dados, foram realizadas análises de componentes principais em vez de análises fatoriais exploratórias, que seriam o método recomendado quando não existem evidências suficientes que demonstrem como os itens de um instrumento devem ser agrupados e avaliados (Damásio, 2012), como é o caso da DP.

Nesse sentido, foi realizada uma revisão de literatura sobre estilos parentais, Terapia do Esquema e DP, assim como uma revisão dos instrumentos psicométricos que mensuram esses construtos. Embora oriundas de diferentes áreas da psicologia, tais abordagens têm em comum versarem sobre o impacto das diferentes formas de interação dos pais com os filhos para o desenvolvimento destes últimos.

A revisão de literatura realizada deixou evidente que, apesar de não ter sido desenvolvida com a finalidade de ser uma abordagem teórica, e sim um material de apoio para pais em relação à criação de seus filhos, a DP possui embasamento teórico robusto, mostrando-se coerente com o que propõem outras abordagens da psicologia, como os estilos parentais e a Terapia do Esquema.

Também foi realizada uma revisão dos instrumentos psicométricos baseados nos estilos parentais e na Terapia do Esquema, já que os instrumentos baseados na DP já haviam sido alvo de revisão. Encontraram-se a versão reduzida do Questionário de Percepção dos Pais (Pasquali et al., 2012) e as versões adaptadas para o Brasil das Escalas de Exigência e Responsividade Parentais (Costa et al., 2000), do Questionário de Estilos Parentais (Boeckel \& Sarriera, 2005) e do Questionário de Estilos e Dimensões Parentais - QEDP (Oliveira et al., 2018), entre outros. No que se refere aos estilos parentais propostos pela Terapia do Esquema, foi encontrada a versão brasileira do Inventário de Estilos Parentais de Young (Valentini, 2009).

Sendo assim, de forma a suprir essa lacuna de medidas válidas, confiáveis e que representem a abrangência do que é proposto pela DP, este artigo apresenta a construção e investigação das evidências de validade e fidedignidade da Escala de Habilidades Parentais em 
Disciplina Positiva (EHPDP), um instrumento de autorrelato para mães com filhos de 4 a 12 anos de idade, que visa mensurar a frequência de determinadas interações que apresentam potencial de suprir necessidades básicas de seus filhos.

\section{Método}

\section{Procedimentos éticos}

O presente estudo foi aprovado pela Comissão de Ética em Pesquisa do Hospital Universitário Pedro Ernesto, Rio de Janeiro, Brasil: Certificado de Apresentação para Apreciação Ética (CAAE) no 16426019.9.0000.5259.

\section{Construção e validade de conteúdo da EHPDP Definição das dimensões e elaboração dos itens da EHPDP}

A revisão teve por objetivo servir de base para a definição das dimensões da EHPDP e a elaboração de seus respectivos itens. Primeiramente, é importante ressaltar que a DP não foi desenvolvida com o intuito de ser uma abordagem teórica, e sim um conjunto de práticas propostas por meio de livros e workshops com a finalidade de auxiliar pais e cuidadores a ensinar habilidades de vida às suas crianças. Sendo assim, foi necessário estruturar uma teoria com base no que é proposto por essa abordagem, para então definir as dimensões do instrumento e elaborar seus respectivos itens. Essa etapa foi realizada por uma psicóloga clínica com experiência em orientação parental e também educadora parental certificada pela Positive Discipline Association, que no momento cursava mestrado em um curso de pós-graduação.

Embora tenham sido encontrados dois instrumentos estrangeiros construídos com a finalidade de mensurar as habilidades parentais da DP, nenhum deles definiu dimensões para os instrumentos. No estudo da Positive Discipline Parenting Scale (Carroll \& Hamilton, 2016), a análise fatorial exploratória (AFE) apontou para uma solução de três fatores, mas o teste Scree Plot indicou que uma solução de um fator seria mais apropriada. A avaliação das cargas fatoriais também indicou que todos os itens carregaram fortemente em um único fator, exceto dois, que foram excluídos, chegando-se a uma versão de setes itens unidimensional. Já no estudo dos Cuestionarios D.I.S.P.O. (Sánchez et al., 2010), são apresentados 28 itens, mas não é explicado o processo de elaboração destes, nem são mencionadas dimensões. Ademais, não foi avaliada a validade fatorial do instrumento; logo, não constam informações nesse sentido.

Sendo assim, por não haver conhecimento prévio em relação às possíveis dimensões da DP, estas foram definidas com base nas informações levantadas na revisão de literatura e dos instrumentos, assim como no conhecimento e na experiência da pesquisadora mencionada. Assim, definiram-se quatro dimensões baseadas nas necessidades básicas das crianças a serem supridas por seus cuidadores (Nelsen et al., 2018): Disciplina Firme e Gentil, Aceitação/ Importância, Capacidade/Autonomia e Habilidades Sociais e de Vida. 
A Disciplina Firme e Gentil consiste na habilidade de regular o comportamento da criança por meio de uma atitude respeitosa e encorajadora (Nelsen, 2015). A Aceitação/Importância se refere à habilidade de tornar perceptível para a criança que ela é aceita, importante e amada (Nelsen, 2015; Wainer et al., 2016). A Capacidade/Autonomia demonstra a habilidade de oferecer à criança oportunidades de perceber que é capaz e de aprender a realizar tarefas adequadas à sua idade sem o auxílio de adultos (Nelsen, 2015; Wainer et al., 2016). As Habilidades Sociais e de Vida consistem na habilidade de auxiliar a criança no desenvolvimento da autoconsciência e autorregulação emocionais, comunicação, avaliação, responsabilidade, solução de problemas e motivação (Glenn \& Nelsen, 2010; Nelsen, 2015).

Os itens foram construídos tomando-se por base as abordagens mencionadas, sendo alguns deles inspirados em itens de instrumentos que medem construtos correlatos, como o questionário utilizado no estudo de McVittie e Best (2009), o QEDP (Oliveira et al., 2018) e os Cuestionarios D.I.S.P.O. (Sánchez et al., 2010). A primeira versão da escala ficou com 36 itens, sendo nove para cada uma das quatro dimensões. Na Tabela 1, encontram-se os itens da primeira versão da EHPDP seguidos de indicação da dimensão para a qual foram construídos.

\section{Análise dos itens pelas juízas experts}

Participaram dessa etapa cinco juízas, diferentes da pesquisadora que criou os itens, sendo quatro psicólogas com grau de doutoras (uma delas também educadora parental em DP) e uma trainer em DP certificada pela Positive Discipline Association, com grau de mestra, todas com elevado conhecimento na área de práticas educativas parentais e duas também em Terapia do Esquema. As avaliadoras foram recrutadas por meio de uma amostra por conveniência, a partir de uma carta-convite enviada por $e$-mail. Elas receberam um arquivo contendo texto explicativo sobre as dimensões da DP e uma planilha com os itens da escala, onde deveriam indicar à qual dimensão se referia cada item e avaliá-lo quanto à clareza de linguagem, pertinência prática e relevância teórica segundo uma escala tipo Likert de 1 (pouquíssima) a 5 (muitíssima). Além disso, foi-Ihes solicitado que realizassem as observações que julgassem necessárias para cada item, registrando críticas, opiniões e sugestões de alterações que pudessem contribuir para a construção do instrumento.

Os dados coletados foram analisados por meio do cálculo do coeficiente de validade de conteúdo - CVC (Hernández-Nieto, 2002) para avaliar a concordância das juízas no que tange ao nível de clareza, pertinência e relevância dos itens, e do coeficiente de concordância Kappa de Cohen, para mensurar a concordância quanto à dimensão a que os itens pertenciam. De acordo com Hernandez-Nieto (2002), CVCs aceitáveis devem indicar uma concordância de $80 \%$ entre os avaliadores. Ao final, cada um dos itens da EHPDP apresentou CVCs entre 0,8 e 1,0 para as dimensões clareza da linguagem, pertinência prática e relevância teórica, e o CVC- 
Total foi de 0,95, 0,98 e 0,99, respectivamente, indicando elevada concordância entre as juízas (Tabela 1).

\section{Tabela 1}

Coeficientes de validade de conteúdo dos itens da EHPDP

\begin{tabular}{|c|c|c|c|}
\hline Item/dimensão & $\mathrm{CVC}_{\text {clareza }}$ & $\mathrm{CVC}_{\text {Pertinência }}$ & $\mathrm{CVC}_{\text {Relevância }}$ \\
\hline $\begin{array}{l}\text { 1. Demonstro afeto abraçando, segurando no colo e beijando } \\
\text { meu/minha filho(a). (Al) }\end{array}$ & 0,99968 & 0,99968 & 0,99968 \\
\hline $\begin{array}{l}\text { 2. Quando meu/minha filho(a) se frustra com algo ou } \\
\text { alguém, eu valido suas emoções dizendo coisas como "Eu } \\
\text { sei que você está triste" e "Eu também estaria triste nessa } \\
\text { situação". (HSV) }\end{array}$ & 0,83968 & 0,95968 & 0,91968 \\
\hline $\begin{array}{l}\text { 3. Ofereço recompensas ao(à) meu/minha filho(a) para } \\
\text { conseguir que ele(a) faça o que eu quero. [item } \\
\text { reverso] (DFG) }\end{array}$ & 0,99968 & 0,99968 & 0,99968 \\
\hline $\begin{array}{l}\text { 4. Uma vez que as regras foram definidas com meu/minha } \\
\text { filho(a), eu cumpro o que foi combinado, mesmo que ele(a) } \\
\text { fique frustrado(a) e/ou tente me convencer a não } \\
\text { cumprir. (DFG) }\end{array}$ & 0,91968 & 0,99968 & 0,99968 \\
\hline $\begin{array}{l}\text { 5. Quando meu/minha filho(a) passa por uma experiência } \\
\text { negativa, pergunto o que aconteceu que pode ter } \\
\text { contribuído para isso e o que ele(a) pode fazer diferente no } \\
\text { futuro para que aquela situação não se repita. (HSV) }\end{array}$ & 0,95968 & 0,99968 & 0,99968 \\
\hline $\begin{array}{l}\text { 6. Quando meu/minha filho(a) realiza alguma tarefa com } \\
\text { sucesso, ressalto seu esforço para gerar aquele } \\
\text { resultado. (CA) }\end{array}$ & 0,99968 & 0,99968 & 0,99968 \\
\hline $\begin{array}{l}\text { 7. Meu filho sabe que eu o levo a sério, ou seja, não apenas } \\
\text { o compreendo, como aceito, amo e respeito. (AI) }\end{array}$ & 0,99968 & 0,99968 & 0,99968 \\
\hline $\begin{array}{l}\text { 8. Levo em consideração as preferências do(a) meu/minha } \\
\text { filho(a) ao fazer planos para a família. (Al) }\end{array}$ & 0,99968 & 0,99968 & 0,99968 \\
\hline $\begin{array}{l}\text { 9. Quando meu/minha filho(a) passa por uma experiência } \\
\text { positiva, pergunto o que ele(a) fez que pode ter contribuído } \\
\text { para esse resultado. (HSV) }\end{array}$ & 0,95968 & 0,91968 & 0,99968 \\
\hline $\begin{array}{l}\text { 10. Meu/minha filho(a) possui tarefas de casa adequadas à } \\
\text { sua idade. (CA) }\end{array}$ & 0,83968 & 0,95968 & 0,99968 \\
\hline $\begin{array}{l}\text { 11. Explico a meu/minha filho(a) os motivos por trás das } \\
\text { regras. (DFG) }\end{array}$ & 0,83968 & 0,99968 & 0,99968 \\
\hline $\begin{array}{l}\text { 12. Eu reconheço e valorizo as pequenas vitórias e/ou boas } \\
\text { atitudes do(a) meu/minha filho(a), encorajando-o(a) a ir } \\
\text { além. (CA) }\end{array}$ & 0,95968 & 0,95968 & 0,95968 \\
\hline $\begin{array}{l}\text { 13. Quando meu/minha filho(a) faz birra, digo que entendo } \\
\text { sua frustração, mas deixo claro que não concordo com a } \\
\text { maneira como decidiu se expressar. (DFG) }\end{array}$ & 0,99968 & 0,95968 & 0,99968 \\
\hline
\end{tabular}




\begin{tabular}{|c|c|c|c|}
\hline Item/dimensão & $\mathrm{CVC}_{\text {clareza }}$ & $\mathrm{CVC}_{\text {Pertinência }}$ & CVC $_{\text {Relevância }}$ \\
\hline $\begin{array}{l}\text { 14. Eu e meu/minha filho(a) costumamos fazer coisas } \\
\text { especiais juntos(as). (Al) }\end{array}$ & 0,99968 & 0,99968 & 0,99968 \\
\hline $\begin{array}{l}\text { 15. Quando reparo que meu/minha filho(a) está sentindo } \\
\text { uma emoção negativa, pergunto se ele(a) gostaria de um } \\
\text { abraço. (Al) }\end{array}$ & 0,99968 & 0,91968 & 0,91968 \\
\hline $\begin{array}{l}\text { 16. Faço ameaças ou prometo coisas a meu/minha filho(a) } \\
\text { que não posso ou não vou cumprir. [item reverso] (DFG) }\end{array}$ & 0,83968 & 0,91968 & 0,99968 \\
\hline 17. Digo a meu/minha filho(a) que o(a) amo. (Al) & 0,99968 & 0,99968 & 0,99968 \\
\hline $\begin{array}{l}\text { 18. Deixo claro para meu/minha filho(a) que a forma como } \\
\text { ele(a) escolhe lidar com suas emoções tem consequências e } \\
\text { que ele(a) é responsável por elas. (HSV) }\end{array}$ & 0,83968 & 0,95968 & 0,95968 \\
\hline $\begin{array}{l}\text { 19. Falo de forma respeitosa com meu/minha filho(a) } \\
\text { mesmo quando ele(a) se comporta mal ou comete algum } \\
\text { erro. (DFG) }\end{array}$ & 0,99968 & 0,99968 & 0,99968 \\
\hline $\begin{array}{l}\text { 20. Conforme meu/minha filho(a) cresce, vou } \\
\text { acrescentando novas responsabilidades adequadas à sua } \\
\text { idade. (CA) }\end{array}$ & 0,99968 & 0,99968 & 0,99968 \\
\hline $\begin{array}{l}\text { 21. Permito que meu/minha filho(a) faça atividades } \\
\text { sozinho(a) mesmo que o resultado não seja o que eu } \\
\text { esperava. (CA) }\end{array}$ & 0,91968 & 0,91968 & 0,99968 \\
\hline $\begin{array}{l}\text { 22. Eu utilizo violência física, determino castigos e/ou retiro } \\
\text { privilégios quando meu/minha filho(a) comete um erro, se } \\
\text { comporta mal ou não vai bem na escola. [item } \\
\text { reverso] (DFG) }\end{array}$ & 0,79968 & 0,95968 & 0,99968 \\
\hline $\begin{array}{l}\text { 23. Se meu/minha filho(a) aparenta sentir uma emoção } \\
\text { negativa, faço perguntas como "O que aconteceu?" e "O que } \\
\text { você está sentindo?". (HSV) }\end{array}$ & 0,95968 & 0,99968 & 0,99968 \\
\hline $\begin{array}{l}\text { 24. Se trato meu/minha filho(a) de forma grosseira, depois } \\
\text { reconheço meu erro e peço desculpas. (HSV) }\end{array}$ & 0,99968 & 0,99968 & 0,95968 \\
\hline $\begin{array}{l}\text { 25. Quando eu e meu/minha filho(a) brigamos, informo que } \\
\text { precisamos de um tempo para nos acalmarmos antes de } \\
\text { conversarmos novamente. (HSV) }\end{array}$ & 0,99968 & 0,99968 & 0,95968 \\
\hline $\begin{array}{l}\text { 26. Convido meu/minha filho(a) a pensar em soluções } \\
\text { quando ele(a) se depara com um problema. (HSV) }\end{array}$ & 0,99968 & 0,99968 & 0,99968 \\
\hline $\begin{array}{l}\text { 27. Quando meu/minha filho(a) vai mal na escola, busco } \\
\text { mostrar que com empenho e dedicação é possível alcançar } \\
\text { resultados melhores. (CA) }\end{array}$ & 0,91968 & 0,87968 & 0,99968 \\
\hline $\begin{array}{l}\text { 28. Convido meu/minha filho(a) a me ajudar em algumas } \\
\text { tarefas domésticas, como fazer uma sobremesa ou dobrar } \\
\text { as roupas limpas. (CA) }\end{array}$ & 0,83968 & 0,99968 & 0,99968 \\
\hline $\begin{array}{l}\text { 29. Encorajo que meu/minha filho(a) se expresse mesmo } \\
\text { quando discorda dos pais. (Al) }\end{array}$ & 0,95968 & 0,99968 & 0,99968 \\
\hline $\begin{array}{l}\text { 30. Permito que meu/minha filho(a) participe da criação das } \\
\text { regras da casa/família quando adequado. (DFG) }\end{array}$ & 0,95968 & 0,99968 & 0,95968 \\
\hline
\end{tabular}




\begin{tabular}{|c|c|c|c|}
\hline Item/dimensão & CVC $_{\text {Clareza }}$ & $\mathrm{CVC}_{\text {Pertinência }}$ & $\mathrm{CVC}_{\text {Relevância }}$ \\
\hline $\begin{array}{l}\text { 31. Deixo meu/minha filho(a) participar da escolha de coisas } \\
\text { como roupas, brinquedos e atividades de lazer, } \\
\text { oferecendo-Ihe algumas possibilidades. (CA) }\end{array}$ & 0,99968 & 0,95968 & 0,99968 \\
\hline $\begin{array}{l}\text { 32. Defino as regras com meu/minha filho(a) com } \\
\text { antecedência. (DFG) }\end{array}$ & 0,91968 & 0,99968 & 0,99968 \\
\hline $\begin{array}{l}\text { 33. Quando meu/minha filho(a) comete um erro, mostro a } \\
\text { ele(a) que todo erro é uma oportunidade de aprender } \\
\text { algo. (HSV) }\end{array}$ & 0,99968 & 0,99968 & 0,99968 \\
\hline $\begin{array}{l}\text { 34. Conforto meu/minha filho(a) quando ele(a) está } \\
\text { triste. (Al) }\end{array}$ & 0,91968 & 0,99968 & 0,95968 \\
\hline $\begin{array}{l}\text { 35. Quando peço a meu/minha filho(a) para fazer } \\
\text { determinada tarefa, explico com clareza o que espero } \\
\text { dele(a) e oriento como deve fazer. (CA) }\end{array}$ & 0,99968 & 0,99968 & 0,99968 \\
\hline $\begin{array}{l}\text { 36. Todo dia dedico um tempo a fazer algo com meu/minha } \\
\text { filho(a). (AI) }\end{array}$ & 0,91968 & 0,91968 & 0,95968 \\
\hline $\mathrm{CVC}_{\text {Total }}$ & 0,94745778 & 0,97748 & 0,9874578 \\
\hline
\end{tabular}

Nota. DFG = Disciplina Firme e Gentil. Al = Aceitação/Importância. CA = Capacidade/Autonomia. HSV = Habilidades Sociais e de Vida.

Os dados referentes à classificação dos itens em uma das quatro dimensões apresentadas foram submetidos ao cálculo do coeficiente de concordância Kappa de Cohen. O resultado geral (Tabela 2) indicou substancial concordância (Ranganathan et al., 2017).

\section{Tabela 2}

Índices Kappa de Cohen e intervalos de confiança das dimensões da EHPDP

\begin{tabular}{cccccc}
\hline & F1 & F2 & F3 & F4 & Kappa geral \\
\hline Kappa & $0,705^{* * *}$ & $0,688^{* * *}$ & $0,653^{* * *}$ & $0,615^{* * *}$ & $0,663^{* * *}$ \\
$(\mathrm{IC} 95 \%)$ & $(0,602-0,809)$ & $(0,584-0,791)$ & $(0,549-0,756)$ & $(0,512-0,718)$ & $(0,603-0,723)$ \\
\hline
\end{tabular}

Nota. ${ }^{* * *} p<0,001$. F1 = Disciplina Firme e Gentil; F2 = Aceitação/Importância; F3 = Capacidade/Autonomia; F4 = Habilidades Sociais e de Vida.

Alguns itens geraram dúvidas nas avaliadoras em relação à dimensão a que pertenciam, o que revelou que poderiam estar relacionados a mais de uma dimensão. Essa hipótese foi cogitada durante a construção dos itens a partir da observação de que alguns dos comportamentos propostos pela DP poderiam vir a suprir mais de uma necessidade básica das crianças. Como a análise fatorial a ser realizada posteriormente poderia trazer mais informações nesse sentido, decidiu-se por manter no instrumento os itens que despertaram tais dúvidas nas juízas.

Os comentários realizados levaram à exclusão de seis itens e à alteração de outros. Por exemplo, uma das juízas ressaltou que o item "Meu filho sabe que eu o levo a sério, ou seja, 
não apenas o compreendo, como aceito, amo e respeito" conteria muitas ações, o que poderia gerar dúvida nos respondentes, que não necessariamente concordariam com todas. Ademais, percebeu-se que, como o item versava sobre uma percepção dos filhos em relação aos pais, isso geraria um conflito em relação à escala de resposta e ao instrumento como um todo, que mediria a frequência de determinadas interações dos pais em relação aos filhos. Logo, optou- se pela exclusão do item.

Já os itens reversos "Faço ameaças ou prometo coisas a meu/minha filho(a) que não posso ou não vou cumprir" e "Eu utilizo violência física, determino castigos e/ou retiro privilégios quando meu/minha filho(a) comete um erro, se comporta mal ou não vai bem na escola" foram excluídos após comentários sobre a possibilidade de gerarem defensividade nos respondentes, já que essas ações são vistas como negativas/violentas pela sociedade. Além disso, o último item possuiria muitas ações, o que poderia prejudicar sua compreensão pelo respondente.

Também foram realizadas reformulações na linguagem de alguns itens, como a troca da expressão "tarefas de casa" para "tarefas domésticas", a fim de evitar a percepção de que o item se referia às tarefas escolares. Além disso, o item "Quando reparo que meu/minha fiIho(a) está sentindo uma emoção negativa" foi alterado para "Quando reparo que meu/minha filho(a) está chateado(a)", de forma a evitar dificuldade de compreensão do item pelo público-alvo.

\section{Análise dos itens pelo público-alvo}

Uma versão de 30 itens da EHPDP foi apreciada por indivíduos pertencentes ao público-alvo, de forma a verificar se eles estavam claros, bem redigidos e de acordo com a realidade dessa população. Participaram dessa etapa três mulheres e dois homens, com idades entre 30 e 38 anos, com filhos de 4 a 12 anos, com graus de escolaridade do ensino fundamental incompleto ao ensino superior, residentes na cidade do Rio de Janeiro, sendo a amostra por conveniência.

Nessa etapa, os respondentes foram convidados a explicar com suas palavras o que compreenderam de cada item. Quando não compreenderam alguma ideia ou expressão, esta foi explicada com outras palavras. Nesses casos, após entenderem o significado da ideia ou expressão, foi solicitado que sugerissem sinônimos mais adequados ou modificações na estrutura do item, de forma a garantir sua compreensão pelo participante.

Os resultados levaram a alterações na redação de diversos itens, como a troca da expressão "se frustra" para "fica chateado" e de "ofereço recompensas" para "faço as vontades". Ademais, os itens "Encorajo que meu/minha filho(a) se expresse mesmo quando discorda de mim" e "Conforto meu/minha filho(a) quando ele(a) está triste" foram excluídos devido à 
dificuldade de compreensão pelo público menos escolarizado, chegando-se à versão-piloto da EHPDP, com 28 itens.

\section{Evidências de validade e fidedignidade da EHPDP Participantes}

Participaram desta pesquisa 281 mães brasileiras, com idades entre 21 e 54 anos $(M=$ 38,$5 ; D P=5,2$ ) e pelo menos um(a) filho(a) entre 4 e 12 anos, que responderam a um formulário virtual após serem recrutadas por meio de postagens em mídias sociais. Todas as participantes consentiram em ter seus dados usados neste estudo, sendo $76,5 \%$ do Sudeste, $7,1 \%$ do Centro-Oeste, $6,4 \%$ do Nordeste, $5 \%$ do Sul e 2,1\% do Norte. Das participantes, 2,8\% estavam residindo no exterior. Entre as participantes, $87,2 \%$ estavam em um relacionamento sério coabitando com o parceiro, 2,8\% em um relacionamento sério sem coabitação com o parceiro e $10 \%$ não estavam se relacionando no momento da coleta de dados. O número de filhos variou de 1 a $9(M=1,8 ; D P=0,83)$ e o tempo de relacionamento de 2 a 360 meses $(M=167,5 ; D P=64,6)$. No tocante à escolaridade, $2,1 \%$ possuíam ensino médio completo; $6 \%$, ensino superior incompleto; $30,6 \%$, ensino superior completo; $8,5 \%$, pós-graduação incompleta; e 52,7\%, pós-graduação completa.

\section{Instrumentos}

Os dados foram obtidos por meio de um formulário autoaplicável composto por três instrumentos psicométricos e um questionário sociodemográfico. Após a validação de conteúdo, a versão-piloto da EHPDP continha 28 itens distribuídos em quatro dimensões: Disciplina Firme e Gentil, Aceitação/Importância, Capacidade/Autonomia e Habilidades Sociais e de Vida. As respondentes utilizaram uma escala tipo Likert de cinco pontos para avaliar os itens de 1 (nunca) a 5 (sempre).

Também foi utilizada uma adaptação brasileira realizada por Oliveira et al. (2018) do QEDP. Esse instrumento é baseado no modelo de Baumrind e possui 32 itens divididos em sete dimensões e três estilos de parentalidade, avaliados por meio de uma escala tipo Likert de cinco pontos, que variam de 1 (nunca) a 5 (sempre). O autoritativo compreende 15 itens divididos em três dimensões (apoio e afeto, regulação e autonomia); o autoritário, 12 itens divididos em três dimensões (coerção física, hostilidade verbal e punição); e o permissivo, cinco itens numa única dimensão (indulgência).

Oliveira et al. (2018) encontraram resultados relativamente bons de validade e fidedignidade para a versão reduzida do QEDP com uma amostra de mães com idade média de 38,44 anos ( $D P= \pm 6,51$ ), com filhos de 3 a 18 anos. A análise fatorial confirmatória confirmou um modelo com três fatores de segunda ordem. O Alfa de Cronbach foi 0,75 para o questionário completo, contudo os índices de fidedignidade variaram de 0,59 a 0,85 entre os fatores 
de primeira e segunda ordens. Além disso, o QEDP apresentou validade convergente com o Inventário de Estilos Parentais (Gomide, 2006). Oliveira et al. (2018) consideraram o QEDP eficaz e confiável para avaliar os diferentes estilos parentais na população brasileira.

Embora alguns fatores do QEDP não tenham apresentado índices de consistência interna aceitáveis, esse instrumento foi escolhido para analisar a validade convergente da EHPDP por ser o mais adequado do contexto brasileiro para mensurar o estilo autoritativo de Baumrind. Como a DP ensina conceitos que são bastante representativos desse estilo (Carroll \& Hamilton, 2016), eram esperadas correlações positivas fortes entre a EHPDP e a dimensão autoritativo do QEDP. Contudo, esperava-se uma correlação negativa entre as dimensões da EHPDP e as dimensões do estilo autoritário e permissivo do QEDP, pois a DP se opõe à prática de interações parentais características desses estilos (Nelsen, 2015).

Também foi utilizada uma adaptação brasileira da Depression, Anxiety and Stress Scale (DASS-21), de Martins et al. (2019). A DASS-21 mensura a afetividade negativa, sendo composta por 21 itens, divididos igualmente em três subescalas: Depressão, Ansiedade e Estresse. Os respondentes devem indicar o quanto cada item se aplicou à sua realidade na última semana por meio de uma escala tipo Likert de quatro pontos que variam de o ("Não se aplicou de maneira nenhuma") a 3 ("Aplicou-se muito ou na maioria do tempo"). Para esta pesquisa, foram efetuadas algumas alterações nessa versão. Alterou-se a redação de dois itens, o período de tempo considerado para avaliação dos sintomas descritos foi o último mês, e utilizou-se uma escala tipo Likert de cinco pontos que variaram de 1 (nunca) a 5 (sempre).

No estudo de Martins et al. (2019), os escores de estudantes universitários de 18 a 35 anos de idade $(M=21,13 ; D P= \pm 2,81)$, por meio de análise fatorial confirmatória, mostraram bom ajuste geral ao modelo teórico de três fatores oblíquos da DASS-21. Porém, a elevada correlação entre eles indicou insuficiente validade discriminativa. Um modelo hierárquico com um fator global (afetividade negativa) foi testado, o qual também revelou bom ajuste geral aos dados e invariância entre homens e mulheres. Para todos os modelos testados, as consistências internas medidas pelo Alfa de Cronbach e pela confiabilidade composta foram superiores a 0,87 para todas as dimensões da DASS-21. Além disso, Zanon et al. (2020) testaram um modelo bifator para a DASS-21, e os resultados indicaram a predominância de um fator global para a medida.

Esse instrumento foi utilizado com a finalidade de gerar evidências de validade discriminante para a EHPDP pelo fato de a afetividade negativa e as habilidades parentais em DP serem construtos bastante diferentes; logo, não deveriam estar associados. Além disso, com base em estudos que encontraram relações entre os estilos e as práticas parentais e aspectos psicológicos dos pais (Mateus, 2016; Rodrigues \& Nogueira, 2016; Borre \& Kliewer, 2014), esperava-se que as dimensões da EHPDP apresentassem correlações negativas com a afetividade negativa medida pela DASS-21. 


\section{Análise dos dados}

Os dados foram analisados por meio de AFE pelo software Factor Analysis versão 10.10.03. Para auxiliar na tomada de decisão quanto ao número de fatores a extrair, utilizou-se o método de Hull (Auerswald \& Moshagen, 2019). O método de extração empregado foi o Minimum Rank Factor Analysis - MRFA (Shapiro \& ten Berge, 2002) numa matriz de correlações policóricas com rotação Promax. A fidedignidade foi verificada por meio do Alfa de Cronbach e da confiabilidade composta. Além disso, para gerar evidências de validade convergente e discriminante para a EHPDP, avaliaram-se as relações das dimensões desta com as do QEDP e da DASS-21, por meio do coeficiente de correlação de Pearson.

\section{Resultados}

Nas análises preliminares, dois itens apresentaram índices de assimetria e curtose extremamente elevados, motivo pelo qual foram excluídos da AFE. Ainda assim, a distribuição multivariada dos escores dos 26 itens remanescentes não apresentou normalidade (índice de Mardia $=392,56 ; C R$ [critical ratio] $=22,94 ; p<0,001$ ). No entanto, a observação da distribuição univariada dos escores revelou que a assimetria e a curtose variaram entre $< \pm 2$ e $< \pm 7$, respectivamente, o que não representa uma violação extrema da normalidade (Finney \& DeStefano, 2013). Então, uma sequência de AFEs foi realizada a partir de uma matriz de correlação policórica. O método de retenção de fatores baseado em autovalores $>1$ indicou a presença de quatro fatores. Porém, o método de Hull (Auerswald \& Moshagen, 2019) recomendou a extração de três fatores para a EHPDP (Tabela 3).

\section{Tabela 3}

Método Hull para seleção do número de fatores comuns

\begin{tabular}{cccc}
\hline $\mathbf{N}^{0}$ de fatores & Bondade de ajuste & Graus de liberdade & Valores Scree Test \\
\hline 0 & 0,180 & 120 & 0,000 \\
1 & 0,368 & 104 & 3,944 \\
2 & 0,413 & 89 & 1,485 \\
3 & 0,441 & 75 & 21,655 \\
4 & 0,438 & 62 & \\
\hline
\end{tabular}

Nota. Índice de bondade de ajuste: Common part Accounted For (CAF). Método para a extração das dimensões: MRFA.

Após atender à recomendação de três fatores, foram excluídos cinco itens por apresentarem cargas fatoriais < 0,32, três itens por apresentarem cargas simultâneas em mais de um fator e dois itens por carregarem em fatores não designados anteriormente ou não pró- 
prios, conforme indicado por Hair et al. (2018). O teste de Bartlett apresentou $\chi 2(120)=$ $2.445,50, p<0,001$ e o teste de Kaiser-Meyer-Olkin $=0,82$, resultados que revelaram a adequação da matriz de correlação desta amostra para a fatorialização.

A solução de três fatores da AFE para a EHPDP, identificados como Habilidades Sociais e de Vida, Aceitação/Importância e Capacidade/Autonomia, revelou uma variância comum total de 12,23, com uma variância comum explicada de 8,94 (73,08\%) da variância comum total. A variância comum não explicada ficou em 3,29. Os 16 itens da EHPDP saturaram mais forte em fatores teoricamente coerentes. A fidedignidade das dimensões da EHPDP, representada pela consistência interna e medida pelo Alfa de Cronbach e pela confiabilidade composta, apresentou valores adequados (Tabela 4).

\section{Tabela 4}

Matriz das cargas fatoriais e comunalidades dos itens da EHPDP

\begin{tabular}{|c|c|c|c|c|}
\hline Itens & F1 & $\mathbf{F} 2$ & F3 & $h^{2}$ \\
\hline $\begin{array}{l}\text { 17. Ajudo meu/minha filho(a) a pensar em soluções quando } \\
\text { percebo que ele(a) está passando por um problema. }\end{array}$ & 0,94 & $-0,04$ & $-0,03$ & 0,95 \\
\hline $\begin{array}{l}\text { 18. Quando meu/minha filho(a) vai mal na escola, busco mostrar } \\
\text { que com empenho e dedicação é possível alcançar } \\
\text { resultados melhores. }\end{array}$ & 0,90 & $-0,17$ & $-0,06$ & 0,86 \\
\hline $\begin{array}{l}\text { 16. Quando meu/minha filho(a) passa por uma experiência ruim, } \\
\text { eu ajudo-o(a) a pensar no que poderia fazer diferente no futuro } \\
\text { para que aquela situação não se repita. }\end{array}$ & 0,80 & 0,07 & 0,06 & 0,93 \\
\hline $\begin{array}{l}\text { 22. Quando meu/minha filho(a) passa por uma experiência boa, } \\
\text { ajudo-o(a) a pensar no que fez que pode ter ajudado a alcançar } \\
\text { aquele resultado. }\end{array}$ & 0,69 & 0,08 & 0,02 & 0,87 \\
\hline $\begin{array}{l}\text { 15. Se meu/minha filho(a) parece estar triste, faço perguntas } \\
\text { como "O que aconteceu?" ou "O que você está sentindo?". }\end{array}$ & 0,59 & 0,08 & 0,05 & 0,76 \\
\hline $\begin{array}{l}\text { 20. Quando meu/minha filho(a) fica chateado(a) com algo ou } \\
\text { alguém, digo coisas como "Eu percebo que você está triste/ } \\
\text { zangado(a)" e/ou "Eu também estaria assim nessa situação". }\end{array}$ & 0,48 & 0,24 & $-0,14$ & 0,52 \\
\hline $\begin{array}{l}\text { 21. Dedico um momento do dia para fazer algo agradável com } \\
\text { meu/minha filho(a). }\end{array}$ & $-0,07$ & 0,95 & $-0,04$ & 1,00 \\
\hline 24. Eu e meu/minha filho(a) fazemos coisas divertidas juntos(as). & 0,02 & 0,83 & 0,04 & 0,84 \\
\hline $\begin{array}{l}\text { 23. Deixo meu/minha filho(a) escolher coisas como roupas, } \\
\text { brinquedos e/ou atividades de lazer, oferecendo opções limitadas } \\
\text { que considero adequadas. }\end{array}$ & 0,24 & 0,37 & 0,11 & 0,61 \\
\hline $\begin{array}{l}\text { 28. Eu levo em consideração as preferências do(a) meu/minha } \\
\text { filho(a) ao fazer planos para a família. }\end{array}$ & 0,12 & 0,35 & 0,04 & 0,51 \\
\hline $\begin{array}{l}\text { 6. Combino com meu/minha filho(a) que ele(a) faça tarefas } \\
\text { domésticas adequadas à sua idade. }\end{array}$ & $-0,05$ & $-0,04$ & 0,94 & 0,91 \\
\hline $\begin{array}{l}\text { 2. Convido meu/minha filho(a) a me ajudar em algumas tarefas } \\
\text { domésticas, mesmo que eu saiba que o resultado não } \\
\text { será perfeito. }\end{array}$ & $-0,21$ & 0,05 & 0,88 & 0,72 \\
\hline
\end{tabular}




\begin{tabular}{lcccc}
\hline \multicolumn{1}{c}{ Itens } & F1 & F2 & F3 & $\boldsymbol{h}^{\mathbf{2}}$ \\
\hline $\begin{array}{l}\text { 7. Permito que meu/minha filho(a) faça atividades sozinho(a) } \\
\text { mesmo que o resultado não seja o que eu esperava. }\end{array}$ & 0,04 & 0,07 & 0,71 & 0,76 \\
$\begin{array}{l}\text { 3. Quando peço a meu/minha filho(a) para fazer algo, digo de } \\
\text { forma clara o que espero dele(a) e explico como deve fazer. }\end{array}$ & 0,17 & $-0,03$ & 0,62 & 0,76 \\
$\begin{array}{l}\text { 10. Conforme meu/minha filho(a) cresce, acrescento à sua rotina } \\
\text { novas responsabilidades. }\end{array}$ & 0,27 & $-0,08$ & 0,62 & 0,75 \\
5. Deixo meu/minha filho(a) participar da criação das regras da & 0,01 & 0,23 & 0,33 & 0,48 \\
casa/família quando adequado. & & & & \\
Correlações & & & & \\
F2 & 0,42 & 1,00 & 0,47 & - \\
F3 & 0,53 & - & - & - \\
Alfa de Cronbach & 0,79 & 0,67 & 0,81 & - \\
Confiabilidade composta & 0,88 & 0,74 & 0,85 & - \\
Variância comum explicada & 3,69 & 2,11 & 3,13 & - \\
& $41,3 \%$ & $23,6 \%$ & $35,1 \%$ & - \\
\hline
\end{tabular}

Nota. F1 = Habilidades Sociais e de Vida. F2 = Aceitação/Importância. F3 = Capacidade/ Autonomia.

A AFE revelou que a dimensão Disciplina Firme e Gentil não estava contemplada na solução encontrada. Dos seis itens construídos para essa dimensão presentes na versão utilizada na coleta de dados, quatro foram excluídos por apresentarem carga fatorial insuficiente e um por apresentar carga em mais de um fator. Além disso, embora o item "Deixo meu/minha filho(a) participar da criação das regras da casa/família quando adequado" também tenha sido inicialmente construído para representá-la, ele apresentou carga fatorial na dimensão Capacidade/Autonomia, passando a fazer parte dessa dimensão. Após análise mais aprofundada do item, percebeu-se que, embora versasse sobre regras, o que seria um tema pertinente à dimensão Disciplina Firme e Gentil, ele poderia estar relacionado ao desenvolvimento da capacidade e autonomia por permitir à criança praticar o ato de definir regras.

Outros dois itens carregaram em fatores diferentes daqueles para os quais foram inicialmente construídos. Os itens "Quando meu/minha filho(a) vai mal na escola, busco mostrar que com empenho e dedicação é possível alcançar resultados melhores" e "Deixo meu/minha filho(a) escolher coisas como roupas, brinquedos e/ou atividades de lazer, oferecendo opções limitadas que considero adequadas" foram construídos para a dimensão Capacidade/Autonomia, mas o primeiro apresentou carga na dimensão Habilidades Sociais e de Vida e o segundo na dimensão Aceitação/Importância.

Conforme mencionado, era esperado que um ou mais itens apresentassem carga em fatores diferentes daqueles para os quais foram construídos, pois na etapa de validação de conteúdo algumas juízas informaram que ficaram em dúvida ao classificarem a dimensão de 
determinados itens. Por exemplo, o item "Deixo meu/minha filho(a) escolher coisas como roupas, brinquedos e/ou atividades de lazer, oferecendo opções limitadas que considero adequadas" poderia ajudar a desenvolver a autonomia e a capacidade por permitir à criança fazer escolhas. Contudo, também poderia fortalecer o senso de Aceitação/Importância por mostrar que os pais levam em consideração seus interesses, o que foi confirmado pela AFE, já que o item apresentou carga nesse fator.

As correlações entre as dimensões da EHPDP e as dimensões do QEDP e da DASS-21, analisadas pelo coeficiente de correlação de Pearson, encontram-se na Tabela 5. Conforme esperado, foram encontradas correlações positivas, estatisticamente significativas, de magnitude forte e moderada entre as dimensões da EHPDP e as dimensões do estilo autoritativo do QEDP, trazendo evidências de validade convergente para a escala construída. Além disso, encontraram-se correlações negativas de magnitudes moderada e fraca entre as dimensões da EHPDP e as dimensões dos estilos autoritário e permissivo do QEDP, sendo algumas significativas. No que tange às correlações entre as dimensões da EHPDP e a afetividade negativa, foram encontradas relações não significativas, negativas e fracas entre elas, o que indica validade discriminante para a EHPDP em relação à DASS-21.

\section{Tabela 5}

Coeficientes de correlação entre as dimensões das medidas utilizadas no estudo

\begin{tabular}{|c|c|c|c|c|c|c|c|c|c|c|c|}
\hline $\begin{array}{c}\text { Dimensão/ } \\
\text { Instrumento }\end{array}$ & 1 & 2 & 3 & 4 & 5 & 6 & 7 & 8 & 9 & 10 & 11 \\
\hline $\begin{array}{l}1 \text { Afetividade } \\
\text { negativa } \\
\text { (DASS-21) }\end{array}$ & 1 & & & & & & & & & & \\
\hline $\begin{array}{l}2 \text { Apoio e afeto } \\
\text { (autoritativo/ } \\
\text { QEDP) }\end{array}$ & $-0,11$ & 1 & & & & & & & & & \\
\hline $\begin{array}{l}3 \text { Regulação } \\
\text { (autoritativo/ } \\
\text { QEDP) }\end{array}$ & $-0,15^{*}$ & $0,54^{* * *}$ & 1 & & & & & & & & \\
\hline $\begin{array}{l}4 \text { Autonomia } \\
\text { (autoritativo/ } \\
\text { QEDP) }\end{array}$ & $-0,12$ & $0,44^{* * *}$ & $0,40 * * *$ & 1 & & & & & & & \\
\hline $\begin{array}{l}5 \text { Coerção física } \\
\text { (autoritário/ } \\
\text { QEDP) }\end{array}$ & $0,25 * * *$ & $-0,06$ & $-0,10$ & $-0,27 * * *$ & 1 & & & & & & \\
\hline $\begin{array}{l}6 \text { Hostilidade } \\
\text { verbal (autoritário/ } \\
\text { QEDP) }\end{array}$ & $0,38 * * *$ & $-0,06$ & $-0,10$ & $-0,29 * * *$ & $0,41 * * *$ & 1 & & & & & \\
\hline $\begin{array}{l}7 \text { Punição } \\
\text { (autoritário/ } \\
\text { QEDP) }\end{array}$ & $0,36 * * *$ & $-0,18 * *$ & $-0,34 * * *$ & $-0,35 * * *$ & $0,41 * * *$ & $0,55^{* * *}$ & 1 & & & & \\
\hline
\end{tabular}




\begin{tabular}{|c|c|c|c|c|c|c|c|c|c|c|c|}
\hline $\begin{array}{c}\text { Dimensão/ } \\
\text { Instrumento }\end{array}$ & 1 & 2 & 3 & 4 & 5 & 6 & 7 & 8 & 9 & 10 & 11 \\
\hline $\begin{array}{l}8 \text { Indulgência } \\
\text { (permissivo/ } \\
\text { QEDP) }\end{array}$ & $0,36 * * *$ & $-0,07$ & $-0,22 * * *$ & $-0,16 * *$ & $0,43 * * *$ & $0,54 * * *$ & $0,53 * * *$ & 1 & & & \\
\hline $\begin{array}{l}9 \text { Habilidades } \\
\text { Sociais e de } \\
\text { Vida (EHPDP) }\end{array}$ & $-0,15^{*}$ & $0,62 * *$ & $0,65 * *$ & $0,46 * *$ & $-0,16^{*}$ & $-0,19 * *$ & $-0,31 * *$ & $-0,31 * *$ & 1 & & \\
\hline $\begin{array}{l}10 \text { Aceitação/ } \\
\text { Importância } \\
\text { (EHPDP) }\end{array}$ & $-0,18^{*}$ & $0,50 * *$ & $0,36 * *$ & $0,57^{* *}$ & $-0,15^{*}$ & $-0,21 * *$ & $-0,22 * *$ & $-0,10$ & $0,43^{* *}$ & 1 & \\
\hline $\begin{array}{l}11 \text { Capacidade/ } \\
\text { Autonomia } \\
\text { (EHPDP) }\end{array}$ & $-0,21 *$ & $0,38 * *$ & $0,50 * *$ & $0,46 * *$ & $-0,18 *$ & $-0,25^{* *}$ & $-0,28 * *$ & $-0,34^{* *}$ & $0,46 * *$ & $0,46 * *$ & 1 \\
\hline
\end{tabular}

Nota. Depression, Anxiety, and Stress Scale (DASS). Questionário de Estilos e Dimensões Parentais (QEDP). Escala de Habilidades Parentais em Disciplina Positiva (EHPDP). ${ }^{*} p<0,05 .{ }^{* *} p<0,01$. $* * * p<0,001$.

Embora não tenha sido objetivo deste estudo analisar as correlações entre as dimensões do QEDP e da DASS-21, cabe relatar que foram encontradas relações não significativas, negativas e fracas entre as dimensões autoritativo (QEDP) e afetividade negativa (DASS-21) e relações positivas muito significativas entre a afetividade negativa e os estilos autoritário e permissivo do QEDP, sendo uma fraca e três moderadas.

\section{Discussão}

O presente estudo teve como objetivos construir e investigar as evidências de validade e fidedignidade de uma medida de habilidades parentais em DP, já que não foram encontradas na literatura nacional escalas similares construídas no Brasil ou adaptadas de outras línguas, e os instrumentos encontrados na literatura estrangeira utilizaram metodologias que despertaram questionamentos em relação à validade deles. O processo de elaboração dos itens baseou-se no conhecimento de uma pesquisadora sobre DP, estilos parentais e Terapia do Esquema e em sua experiência na orientação parental individual ou em grupo, assim como em revisão da literatura e dos instrumentos psicométricos referentes às abordagens citadas. Esta revisão também trouxe respaldo teórico para a DP, que foi elaborada em forma de manuais para mães e pais e não como um referencial teórico-técnico, em especial pelas semelhanças em relação ao estilo autoritativo e às necessidades fundamentais previstas pela Terapia do Esquema (Carroll \& Hamilton, 2016; Wainer et al., 2016).

A validade se refere ao grau em que um instrumento representa com precisão o construto que visa medir (Hair et al., 2018). A análise das juízas, o cálculo do CVC e do coeficiente de concordância Kappa de Cohen e a análise do público-alvo trouxeram evidências de validade de conteúdo para a EHPDP. A AFE indicou evidências de validade fatorial e os testes de 
correlação da EHPDP com o QEDP e a DASS-21 apontaram evidências de validade convergente e discriminante. Essas validades demonstram que a EHPDP representa o construto habilidades parentais em DP.

Já a fidedignidade, também chamada de confiabilidade, é a capacidade de um instrumento reproduzir um resultado de forma consistente no tempo e no espaço (Souza et al., 2017). A consistência interna medida pelo Alfa de Cronbach geralmente é considerada aceitável quando acima de 0,7 (Hair et al., 2018). Neste estudo, esse critério foi atendido pelas dimensões Habilidades Sociais e de Vida $(0,79)$ e Capacidade/Autonomia $(0,81)$, mas não pela dimensão Aceitação/Importância $(0,67)$. Entretanto, alguns pesquisadores consideram coeficientes de 0,6 a 0,7 o limite inferior de aceitabilidade (Hair et al., 2018). Portanto, pode-se dizer que a EHPDP atendeu a esse critério, trazendo evidências quanto à confiabilidade do instrumento.

Os resultados encontrados levaram a uma versão final da EHPDP com 16 itens divididos em três dimensões, sendo seis itens para a dimensão Habilidades Sociais e de Vida, quatro para a dimensão Aceitação/Importância e seis para a dimensão Capacidade/Autonomia. As dimensões refletem as necessidades básicas das crianças a serem supridas por seus cuidadores.

Na dimensão Habilidades Sociais e de Vida, são encontradas interações que estimulam a nomeação e aceitação das emoções, a resolução de problemas, a motivação e a avaliação (Glenn \& Nelsen, 2010; Nelsen, 2015). Já a dimensão Aceitação/Importância contempla interações que promovem a percepção de que as preferências e interesses da criança são respeitados e de que seus cuidadores buscam estar com ela e fazer coisas prazerosas juntos, fortalecendo a crença de que são aceitas e importantes (Glenn \& Nelsen; Nelsen, 2015; Wainer et al., 2016). Por sua vez, na dimensão Capacidade/Autonomia, encontram-se interações nas quais a criança tem a oportunidade de desenvolver sua autonomia e a crença de que é capaz, como por meio da prática de atividades sozinha e/ou com a monitoria/orientação clara dos pais (Glenn \& Nelsen, 2010; Nelsen, 2015; Wainer et al., 2016).

As correlações negativas de magnitudes moderada e fraca encontradas entre as dimensões da EHPDP e as dimensões dos estilos autoritário e permissivo do QEDP, algumas delas significativas, demonstram coerência com a proposta da DP. Segundo Nelsen (2015), a DP se afasta da rigidez e da permissividade, que são características do estilo autoritário e do permissivo, respectivamente. Também foram encontradas relações não significativas, negativas e fracas entre as dimensões autoritativo (QEDP) e afetividade negativa (DASS-21), e relações positivas muito significativas entre a afetividade negativa e os estilos autoritário e permissivo do QEDP. Resultados similares foram encontrados por Mateus (2016) entre o estilo firme (autoritativo) e a dimensão ansiedade e insônia, o estilo autoritário e as dimensões ansiedade e insônia e depressão grave, e o estilo permissivo e a dimensão ansiedade e insônia. 
Tais resultados sugerem que existem relações entre a forma como a parentalidade é exercida e aspectos psicológicos dos pais.

Impactos na saúde mental de cuidadores poderiam comprometer sua habilidade de exercer o papel parental (Borre \& Kliewer, 2014), levando à utilização de práticas autoritárias e permissivas. Por sua vez, estilos e práticas parentais negativos poderiam representar um fator de risco para a saúde mental dos pais. Como os filhos de pais autoritários e permissivos costumam apresentar mais problemas de comportamento (Lamborn et al., 1991; Tavassolie et al., 2016), as interações pais-filhos pautadas nessa abordagem tendem a ser mais estressoras para os pais, o que poderia prejudicar sua saúde mental. Pesquisas futuras serão necessárias para investigar como se dá a dinâmica entre as variáveis "estilos parentais" e "saúde mental", permitindo compreender melhor a importância do apoio psicológico e dos treinamentos em habilidades parentais na vida dos indivíduos que exercem a parentalidade.

Embora tenham sido encontradas evidências de validade e fidedignidade para a medida construída, também é importante destacar as limitações desta pesquisa. Primeiramente, deve-se ressaltar que a proposta teórica da DP sugere a existência de quatro dimensões (Nelsen et al., 2018) e que os resultados desta pesquisa encontraram apenas três dimensões adequadas à teoria. A operacionalização da dimensão Disciplina Firme e Gentil se mostrou mais desafiadora que a das demais, o que pode ter levado à construção de itens que não a representassem. A DP propõe que as mães e os pais sejam firmes e gentis simultaneamente, tornando mais complexa a operacionalização das categorias comportamentais em itens. Logo, recomenda-se que novas investidas científicas produzam e testem novos itens para a dimensão Disciplina Firme e Gentil, contemplando interações nas quais os cuidadores busquem regular o comportamento da criança por meio do estabelecimento firme e gentil de limites. Assim, espera-se que seja construída uma versão da EHPDP que possa representar ainda mais extensamente o que é proposto pela DP.

No que tange à amostra, embora a coleta de dados tenha incluído mães e pais, a amostra atual foi de mães, visto que o percentual de participantes do sexo masculino foi muito baixo (11\%). Uma análise sistemática realizada por Ruiz-Zaldibar et al. (2018) sobre competência dos pais e estratégias de intervenção encontrou 15 estudos conduzidos na América do Norte, Europa e Ásia, dos quais quatro incluíam apenas mães em suas amostras, um excluiu os pais da análise porque representavam $6 \%$ dos participantes, e, nos demais, com amostras de pais e mães, a representação do sexo feminino foi acima de $90 \%$ em todos. Isso demonstra que a dificuldade de encontrar participantes do sexo masculino é uma questão recorrente em pesquisas relacionadas à parentalidade. Além disso, o nível de escolaridade das participantes não foi representativo da população brasileira.

Sendo assim, recomenda-se que estudos futuros incluam também pais e outros tipos de cuidadores, de níveis de escolaridade mais diversos, de forma a garantir amostras mais 
representativas das estruturas familiares brasileiras. Sugere-se também que novas empreitadas abordem amostras mais abrangentes em número e na extensão do território nacional.

A construção e a análise das evidências de validade da EHPDP representam uma importante contribuição na avaliação das interações das mães com os filhos. A escala poderá preencher uma lacuna existente na literatura nacional e internacional em relação às medidas de habilidades parentais em DP.

Ademais, a utilidade das medidas de habilidades parentais não se restringe à pesquisa. Elas também podem ser utilizadas no contexto clínico da orientação parental e nos treinamentos em habilidades parentais para grupos, permitindo uma avaliação rápida da ocorrência e frequência de interações positivas dos pais com os filhos. Com isso, psicólogos poderão realizar uma orientação parental mais acurada, facilitando o aumento do repertório de habilidades que promovam o desenvolvimento social, emocional e cognitivo de seus filhos.

Por fim, cabe ressaltar que a existência de uma medida válida e confiável para mensurar habilidades parentais em DP permitirá que pesquisas futuras investiguem se os treinamentos para pais propostos pela DP são capazes de promover o desenvolvimento das habilidades parentais de seus participantes. Em caso positivo, também será possível avaliar se essas habilidades conseguem se manter ao longo do tempo. 


\section{Referências}

Auerswald, M., \& Moshagen, M. (2019). How to determine the number of factors to retain in exploratory factor analysis: A comparison of extraction methods under realistic conditions. Psychological Methods, 24(4), 468-491. https://doi.org/10.1037/metoooo200

Baumrind, D. (1966). Effects of authoritative parental control on child behavior. Child Development, 37(4), 887-907. https://doi.org/10.2307/1126611

Baumrind, D. (1967). Child care practices anteceding three patterns of preschool behavior. Genetic Psychology Monographs, 75(1), 43-88. https://psycnet.apa.org/record/1967-05780-001

Baumrind, D. (1971). Current patterns of parental authority. Developmental Psychology Monograph, 4(1, Pt. 2), 1-103. https://dx.doi.org/10.1037/hoo30372

Boeckel, M. G., \& Sarriera, J. C. (2005). Análise fatorial do Questionário de Estilos Parentais (PAQ) em uma amostra de adultos jovens universitários. Psico-USF, 10(1), 1-9. https://doi.org/10.1590/ S1413-82712005000100002

Boeckel, M. G., \& Sarriera, J. C. (2006). Estilos parentais, estilos atribucionais e bem-estar psicológico em jovens universitários. Revista Brasileira de Crescimento e Desenvolvimento Humano, 16, 53-65. http://pepsic.bvsalud.org/scielo.php?script=sci_abstract\&pid=S0104-12822006000300007

Borre, A., \& Kliewer, W. (2014). Parental strain, mental health problems, and parenting practices: A longitudinal study. Personality and Individual Differences, 68, 93-97. https://doi.org/10.1016/j. paid.2014.04.014

Carroll, P., \& Hamilton, W. K. (2016). Positive Discipline Parenting Scale: Reliability and validity of a measure. Journal of Individual Psychology, 72(1), 60-74. https://dx.doi.org/10.1353/jip.2016.0002

Costa, F. T., Teixeira, M. A. P., \& Gomes, W. B. (2000). Responsividade e exigência: Duas escalas para avaliar estilos parentais. Psicologia: Reflexão e Crítica, 13(3), 465-473. https://dx.doi.org/10.1590/ S0102-79722000000300014

Damásio, B. F. (2012). Uso da análise fatorial exploratória em psicologia. Avaliação Psicológica, 11(2), 213-228. http://pepsic.bvsalud.org/scielo.php?script=sci_arttext\&pid=S1677-04712012000200007 \&lng $=p t \& t \operatorname{lng}=p t$

Finney, S. J., \& DeStefano, C. (2013). Non-normal and categorical data in structural equation modeling. In G. R. Hancock \& R. O. Mueller (Eds.), Structural equation modeling: A second course (269-314). IAP.

Glenn, H. S., \& Nelsen, J. (2010). Raising self-reliant children in a self-indulgent world: Seven building blocks for developing capable young people. Prima Publishing and Communications.

Gomide, P. I. C. (2006). Inventário de Estilos Parentais - IEP. Vozes.

Granja, M. B., \& Mota, C. P. (2018). Estilos parentais, adaptação académica e bem-estar psicológico em jovens adultos. Análise Psicológica, 36(3), 311-326. https://psycnet.apa.org/record/2019-18896-004

Hair, J. F., Babin, B. J., Anderson, R. E., \& Black, W. C. (2018). Multivariate data analysis. Cengage Learning EMEA.

Hernández-Nieto, R. A. (2002). Contribuciones al análisis estadístico. Universidad de Los Andes, IESINFO. 
Hutz, C. S., \& Bardagi, M. P. (2006). Indecisão profissional, ansiedade e depressão na adolescência: A influência dos estilos parentais. Psico-USF, 11(1), 65-73. https://dx.doi.org/10.1590/ S1413-82712006000100008

Lamborn, S. D., Mounts, N. S., Steinberg, L., \& Dornbusch, S. M. (1991). Patterns of competence and adjustment among adolescents from authoritative, authoritarian, indulgent, and neglectful families. Child Development, 62(5), 1049-1065. https://dx.doi.org/10.2307/1131151

Martins, B. G., Silva, W. R., Maroco, J., \& Campos, J. A. D. B. (2019). Escala de Depressão, Ansiedade e Estresse: Propriedades psicométricas e prevalência das afetividades. Jornal Brasileiro de Psiquiatria, 68(1), 32-41. https://dx.doi.org/10.1590/0047-2085000000222

Mateus, I. S. M. (2016). Relação entre os estilos e práticas parentais e saúde mental. Um estudo com a população geral. [Dissertação de mestrado não publicada]. Universidade do Algarve.

McVittie, J., \& Best, A. (2009). The impact of Adlerian-based parenting classes on self-reported parental behavior. Journal of Individual Psychology, 65(3), 264-285. https://psycnet.apa.org/ record/2009-23639-006

Nelsen, J. (2015). Disciplina Positiva. Manole.

Nelsen, J., Erwin, C., \& Duffy, R. A. (2018). Disciplina Positiva para crianças de o a 3 anos. Manole.

Oliveira, T. D., Costa, D. S., Albuquerque, M. R., Malloy-Diniz, L. F., Miranda, D. M., \& de Paula, J. J. (2018). Cross-cultural adaptation, validity, and reliability of the Parenting Styles and Dimensions Questionnaire - Short Version (PSDQ) for use in Brazil. Revista Brasileira de Psiquiatria, 40(4), 410-419. https://dx.doi.org/10.1590/1516-4446-2017-2314

Paiva, F. \& Ronzani, T. (2009). Estilos parentais e consumo de drogas entre adolescentes: Revisão sistemática. Psicologia em Estudo, 14(1), 177-183. https://dx.doi.org/10.1590/ S1413-73722009000100021

Pasquali, L., Gouveia, V. V., Santos, W. S., Fonsêca, P. N., Andrade, J. M., \& Lima, T. J. S. (2012). Questionário de Percepção dos Pais: Evidências de uma medida de estilos. Paidéia, 22(52), 155-164. https://dx.doi.org/10.1590/S0103-863X2012000200002

Ranganathan, P., Pramesh, C. S., \& Aggarwal, R. (2017). Common pitfalls in statistical analysis: Measures of agreement. Perspectives in Clinical Research, 8(4), 187-191. https://doi.org/10.4103/picr. PICR_123_17

Rodrigues, O. M. P. R., \& Nogueira, S. C. (2016). Práticas educativas e indicadores de ansiedade, depressão e estresse maternos. Psicologia: Teoria e Pesquisa, 32(1), 35-44. https://doi.org/10.1590/0102-37722016012293035044

Ruiz-Zaldibar, C., Serrano-Monzó, I., \& Mujika, A. (2018). Programas de competência dos pais para promover parentalidade positiva e estilos de vida saudáveis em crianças: Uma análise sistemática. Jornal de Pediatria, 94(3), 238-250. https://doi.org/10.1016/j.jped.2017.07.019

Sánchez, J. J. M, Martínez, M. E. de J., Martínez, M. C. R., \& Correa, A. G. (2010). Análisis de las propriedades psicométricas de los cuestinarios D.I.S.P.O. (Disciplina Positiva: Evaluación de la responsabilidad y corresponsabilidad familiar). International Journal of Developmental and Educational Psychology, 3(1), 591-600. https://www.redalyc.org/articulo.oa?id=349832326064

Shapiro, A., \& ten Berge, J. M. F. (2002). Statistical inference of minimum rank factor analysis. Psychometrika, 67(1), 79-94. https://dx.doi.org/10.1007/BF02294710 
Souza, A. C. de, Alexandre, N. M. C., \& Guirardello, E. de B. (2017). Propriedades psicométricas na avaliação de instrumentos: Avaliação da confiabilidade e da validade. Epidemiologia e Serviços de Saúde, 26(3), 649-659. https://doi.org/10.5123/S1679-49742017000300022

Tavassolie, T., Dudding, S., Madigan, A.L., Thorvardarson, E., \& Winsler, A. (2016). Differences in perceived parenting style between mothers and fathers: Implications for child outcomes and marital conflict. Journal of Child and Family Studies, 25, 2055-2068. https://doi.org/10.1007/ s10826-016-0376-y

Uji, M., Sakamoto, A., Adachi, K., \& Kitamura, T. (2014) The impact of authoritative, authoritarian, and permissive parenting styles on children's later mental health in Japan: Focusing on parent and child gender. Journal of Child and Family Studies, 23, 293-302. https://doi.org/10.1007/ s10826-013-9740-3

Valentini, F. (2009). Estudo das propriedades psicométricas do Inventário de Estilos Parentais de Young no Brasil. [Dissertação de mestrado não publicada]. Universidade Federal do Rio Grande do Norte.

Wainer, R., Paim, K., Erdos, R., \& Andriola, R. (Orgs). (2016). Terapia cognitiva focada em esquemas: Integração em psicoterapia. Artmed.

Weber, L., Brandenburg, O., \& Viezzer, A. P. (2003). A relação entre o estilo parental e o otimismo da criança. Psico-USF, 8(1), 71-79. https://dx.doi.org/10.1590/S1413-82712003000100010

Zanon, C., Brenner, R. E., Baptista, M. N., Vogel, D. L., Rubin, M., Al-Darmaki, F. R., Gonçalves, M., Heath, P. J., Liao, H. Y., Mackenzie, C. S., Topkaya, N., Wade, N. G., \& Zlati, A. (2020). Examining the dimensionality, reliability, and invariance of the Depression, Anxiety, and Stress Scales-21 (DASS-21) across eight countries. Assessment, 28(6), 1531-1544. https://doi. org/10.1177/1073191119887449

\section{EQUIPE EDITORIAL}

Editora-chefe

Cristiane Silvestre de Paula

\section{Editores associados}

Alessandra Gotuzo Seabra

Ana Alexandra Caldas Osório

Luiz Renato Rodrigues Carreiro

Maria Cristina Triguero

Veloz Teixeira

Editores de seção

"Avaliação Psicológica"

Alexandre Serpa

André Luiz de Carvalho Braule Pinto

Luiz Renato Rodrigues Carreiro

Vera Lúcia Esteves Mateus

"Psicologia e Educação"

Alessandra Gotuzo Seabra

Carlo Schmidt

Regina Basso Zanon

"Psicologia Social e Saúde das
Populações"
Enzo Banti Bissoli
Marina Xavier Carpena

\section{"Psicologia Clínica"}

Carolina Andrea Ziebold Jorquera

Julia Garcia Durand

Natalia Becker

"Desenvolvimento Humano"
Maria Cristina Triguero
Veloz Teixeira
Rosane Lowenthal

\section{Suporte técnico}

Maria Fernanda Liuti

Bento da Silva

Camila Fragoso Ribeiro
PRODUÇÃO EDITORIAL

Coordenação editorial

Ana Claudia de Mauro

\section{Estagiários editoriais}

Júlia Lins Reis

Pietro Menezes

Élcio Carvalho

\section{Preparação de originais}

Carlos Villarruel

\section{Revisão}

Vera Ayres

\section{Diagramação}

Acqua Estúdio Gráfico 